\title{
Genetic studies of the pattern of floral pigmentation in Clarkia gracilis
}

\author{
L. D. Gottlieb and \\ V. S. Ford
}

Department of Genetics,

University of California,

Davis, CA 95616, U.S.A.

The flowers of Clarkia gracilis subsp. sonomensis have large petals each with a large, central, red-purple spot while the flowers of subsp. gracilis are small and unspotted. Other pigmentation (anthocyanin) patterns also vary within and between these subspecies. We carried out a genetic analysis of differences in floral patterns and petal size. $A$ novel basal petal spot appeared in the $F_{2}$. The analysis indicated that the novel petal spot was specified by an allele in subsp. gracilis at a locus governing spot position. This allele is not normally expressed in subsp. gracilis because of the action of a modifier gene at a second locus. The study also indicated single factor inheritance for presence versus absence of pigmentation on the hypanthium, stamens, and the lower portion of the petals. Multifactorial inheritance was observed for differences in petal length and width. Most of the possible recombinant floral patterns were recovered in the $F_{2}$ and $F_{3}$. This system can be used to study developmental regulation of floral traits as well as ecological relationships between floral pattern and pollination system. The recovery of a normally unexpressed allele for basal petal spot points to the difficulty of extrapolating from phenotypic analysis to an understanding of morphological evolution.

\section{INTRODUCTION}

Genetic analyses of floral patterning have been carried out in a number of species including Antirrhinum majus (Fincham and Harrison, 1967), Gossypium sps. (Harland, 1929; Hutchinson, 1932), Nemesia strumosa (Riley, 1945a, b, 1948, 1949), Papaver rhoeas (Philp, 1933), Petunia (Cornu and Maizonnier, 1983), Pharbitis nil (Imai, 1931), Ipomaea purpurea (Ennos and Clegg, 1983), and Primula sinensis (De Winton and Haldane, 1933). These studies suggest that allelic substitutions or the joint action of several genes can change particular aspects of a floral pattern or engender entirely new patterns. The new patterns result from specific changes in the type, presence, relative intensity, and localisation of pigments on the corolla and other floral organs.

A genetic analysis of floral patterning in Clarkia (Onagraceae) is of particular interest because it can contribute to our knowledge of evolution in this genus, which has long been used as a model system for studies in plant systematics. Phylogeny and evolutionary divergence in Clarkia have been studied by means of traditional systematics (Lewis and Lewis, 1955; Lewis, 1973), by isozyme analysis (Gottlieb and Weeden, 1979) and by restriction fragment analysis of chloroplast DNA (Sytsma and Gottlieb, 1986a,b); for a review see Gottlieb (1986). Conspicuous floral differences distinguish Clarkia species, and it has been suggested that the evolution of novel Clarkia floral patterns may result in changes in pollinator preference and thus contribute to speciation (MacSwain, Raven and Thorp, 1973). Since Clarkia species are fully reproductively isolated, the genetic basis of floral differences cannot generally be determined. However, floral pigmentation variants in $C$. amoena and $C$. rubicunda were analysed genetically by Rasmuson (1921). Also, selfing and outcrossing variants in $C$. xantiana differ in petal size and time of stigma maturation. The genetic basis of these traits was studied by Moore and Lewis (1965).

Clarkia gracilis is an allotetraploid species derived from the diploid species $C$. amoena and an extinct species related to $C$. lassenensis and $C$. arcuata (Abdel-Hameed and Snow, 1968, 1972). There are four interfertile subspecies. C. gracilis subsp. gracilis has small pink unspotted petals, subsp. sonomensis has large pink petals each with a large, central, red-purple spot, and subspp. albicaulis and tracyi have large petals with an intense red-purple band across the base. The 
reddish-purple colours of Clarkia species result from the presence of glucosidic derivatives of malvidin, supplemented with derivaties of cyanidin and delphinidin (Soltis, 1986). Bands and spots appear to result from locally elevated levels of the same pigments that provide the background colour (Dorn and Bloom, 1984).

In this paper we describe a genetic analysis of aspects of the patterns distinguishing subspp. gracilis and sonomensis. Segregation of factors governing size and pigmentation resulted in a wide variety of floral patterns, some of which resemble those of other species of Clarkia. We briefly discuss ways in which this system can be used to address both ecological and developmental hypotheses, thus testing and expanding our understanding of evolution in the genus. We also discuss the evolutionary significance of the finding of an unexpressed allele for basal petal spot in subsp. gracilis.

\section{MATERIALS AND METHODS}

\section{Plants}

Plants for the present study were grown from seed collected in natural populations in northern California. Clarkia gracilis subsp. gracilis 74B was collected in Lake County (Bartlett Springs Road, $3.2 \mathrm{~km}$ from junction with Highway 20 ), and $C$. gracilis subsp. sonomensis 8513 in Sonoma County (junction of Franz Valley School Road and Petrified Forest Road). The two subspecies resemble each other closely at 14 loci identified by electrophoretic analysis of their enzyme products (Holsinger and Gottlieb, 1988). Subspecies gracilis is predominately self-pollinating while subsp. sonomensis is generally outcrossing (AbdelHameed and Snow, 1968). Two $F_{1}$ progenies were made between individuals from the two populations. To assure their hybridity, the selfing subsp. gracilis was used as the pollen parent and subsp. sonomensis as the female parent (its flowers were emasculated several days prior to pollination). An $F_{1}$ individual was self-pollinated to make the $F_{2}$. Other $F_{1}$ plants were backcrossed to plants of each parental population to make two first generation backcross progenies of each type. Selected $F_{2}$ plants were selfed to make $F_{3}$ progenies.

\section{Growth conditions}

Samples of both parental populations, the two $F_{1}$ 's, the $F_{2}$ and two backcrosses to each parent were grown out together in Davis in the late spring,
1986 , and the $F_{3}$ progenies were grown in the fall, 1986. Following germination, plants were initially potted in a $3: 1$ mixture of sand and peat moss, with complete fertilizer, in cell-paks (about $50 \mathrm{~cm}^{3}$ of soil per seedling). They were placed in growth chambers with a 12 hour light period (mixed fluorescent and incandescent lamps, about 300 microeinsteins $\mathrm{m}^{-2} \mathrm{~s}^{-1}$ ) at $18^{\circ} \mathrm{C}$ and a 12 hour dark period at $13^{\circ} \mathrm{C}$. After 4 weeks, the seedlings were repotted into $10 \mathrm{~cm}$ plastic pots, grown for two additional weeks at a 14 hour light period at $24^{\circ} \mathrm{C}$ and 10 hour dark period at $18^{\circ} \mathrm{C}$ (to accelerate the onset of flowering), then transferred to an outdoor lathhouse on 11 June 1986. The plants began to flower on July 1 . The pots were randomised both in the growth chamber and in the lathhouse. The $F_{3}$ progenies were grown in growth chambers until flowering and then were transferred to a greenhouse.

\section{Measurements}

The following measurements and observations were made for each plant.

(a) Petal length and width were measured on the first or second flower to open.

(b) Presence or absence of anthocyanin pigments was scored for the anthers, filaments and inner surface of the hypanthium. (The hypanthium is above the apex of the ovary and is generally interpreted as a fusion of the bases of the sepals, petals and filaments.)

(c) Normal pink pigmentation versus "white cup" was scored for the basal part of the front (adaxial) surface of the petals. In the white cup phenotype, the basal quarter of each petal lacks anthocyanin pigments and is bright white, giving the appearance of a white cup at the base of the flower. In subsp. sonomensis and in the backcrosses to subsp. sonomensis, it was often possible to distinguish between a bright white cup (no pigmentation), a pale cup (slight pigmentation) and no cup (normal pink pigmentation). In the more complex segregating background of the $F_{2}$, it was not possible to distinguish the latter two categories reliably so these were pooled. Plants with white cup were more distinctive, but some confusion between white cup and pale cup may have occurred.

(d) Presence or absence of central spot was scored for both the front and back (abaxial) petal surfaces. Presence and character of basal spot on the front surface was also scored. The expression of this basal "spot" was quite vari- 
able but plants could be divided into four categories. Some plants, such as those of subsp. sonomensis, completely lacked any basal pigmentation beyond the background level ("no spot"). Some plants, such as subsp. gracilis and the $F_{1}$, had an indistinct area of slightly more intense pigmentation which we refer to as a "smudge." Some $F_{2}$ and $F_{3}$ plants had an "intense basal spot" consisting, like the central spot of subsp. sonomensis, of an aggregation of longitudinal files of brightly pigmented cells. The fourth category of plants typically exhibited variation from flower to flower on single individuals, ranging from no spot to smudge to tiny flecks of bright colour to small but distinct basal spots, although on each flower the four petals were alike. These plants with variable expression were assigned to the category of "weak spot."

\section{RESULTS}

\section{Petal size}

The mean, coefficient of variation (standard deviation as a percentage of the mean), and sample size for petal length and width are presented in table 1 . The petals of subsp. sonomensis were on the average about two and a half times longer than those of subsp. gracilis and nearly four times wider. Average length exceeded average width in both subspecies, but the small petals of subsp. gracilis were much longer than wide, by a factor of two in some individuals, while the large petals of subsp. sonomensis were more nearly "square," with length equal to width in some individuals (data not shown). The $F_{1}$ plants were intermediate in petal length and width.

In the $F_{2}$, petal length and width showed a continunus pattern of variability (fig. 1). The two traits were significantly more variable in the $F_{2}$ than in the $F_{1}$ (for petal length, $F=2 \cdot 85$, $\mathrm{df}=$ $237,50, P<0.001$; for petal width $F=4 \cdot 22, \mathrm{df}=$ $237,50, \quad P<0.001)$. Since the variances are different, we compared petal length and width in the $F_{1}$ and $F_{2}$ using both the approximate $t$-test (Sokal and Rohlf, 1981, p. 411) and the Mann Whitney $U$ Test with $U$ statistics converted to standard deviates (Sokal and Rohlf, 1981, p. 434). Petals were larger both in length $\left(t^{\prime}=8 \cdot 5, z=6 \cdot 3\right.$, $P<0.001$ for both tests) and in width $\left(t^{\prime}=2 \cdot 3\right.$, $z=2 \cdot 3, P<0.05$ for both tests). A few individuals had petals as small as those of subsp. gracilis but none recovered the mean petal length of subsp. sonomensis. The backcross progenies also showed continuous variation in petal length and width, and the backcross to subsp. sonomensis failed to recover the parental mean. Petal length and width were significantly correlated in the $\mathrm{F}_{2}(r=0.72$, $n=238$ ) and both backcrosses (data not given), probably indicating that at least some factors govern both traits. However, the "square" shape characteristic of the large subsp. sonomensis petals was recovered in all sizes of petals in the $F_{2}$, suggesting some recombination of factors governing length and width, or of factors governing size and shape. The elongated shape characteristic of subsp. gracilis was recovered only in small-petalled $F_{2}$ plants. Overall the results suggest that control of petal length and width is polygenic.

\section{Front petal spot position}

Summary data on petal spots are presented in table 2 for the parental samples, $F_{1}, F_{2}$ and backcross progenies (two replicates for each backcross) and in table 3 for seven $F_{3}$ progenies. The petals of subsp. sonomensis had a large central spot but no basal spot (fig. 2(A)). Those of subsp. gracilis lacked spots (fig. 2(A)) but a faint basal "smudge" was discernible in our original experiment,

Table 1 Means and coefficients of variation (CV) for petal length and width in subsp. gracilis and subsp. sonomensis and their hybrids

\begin{tabular}{|c|c|c|c|c|c|}
\hline & \multirow[b]{2}{*}{$n$} & \multicolumn{2}{|c|}{ Petal length (mm) } & \multicolumn{2}{|c|}{ Petal width $(\mathrm{mm})$} \\
\hline & & $\bar{x}$ & $\mathrm{CV}$ & $\bar{x}$ & $\mathrm{CV}$ \\
\hline subsp. gracilis & 32 & $12 \cdot 7$ & $12 \cdot 8$ & $7 \cdot 2$ & $9 \cdot 3$ \\
\hline subsp. sonomensis & 39 & $32 \cdot 0$ & 8.9 & $26 \cdot 1$ & $8 \cdot 6$ \\
\hline $\mathrm{F}_{1}^{\mathrm{a}}$ & 51 & $23 \cdot 6$ & $7 \cdot 8$ & $16 \cdot 5$ & $8 \cdot 2$ \\
\hline $\mathrm{F}_{2}$ & 238 & $20 \cdot 8$ & $15 \cdot 0$ & $15 \cdot 9$ & $17 \cdot 4$ \\
\hline Backcrosses to subsp. gracilis $^{\mathrm{a}}$ & 144 & $17 \cdot 8$ & $11 \cdot 6$ & $13 \cdot 1$ & $14 \cdot 2$ \\
\hline Backcrosses to subsp. sonomensis ${ }^{a}$ & 144 & $25 \cdot 9$ & $9 \cdot 5$ & $19 \cdot 5$ & $10 \cdot 3$ \\
\hline
\end{tabular}

"Two progenies combined. 

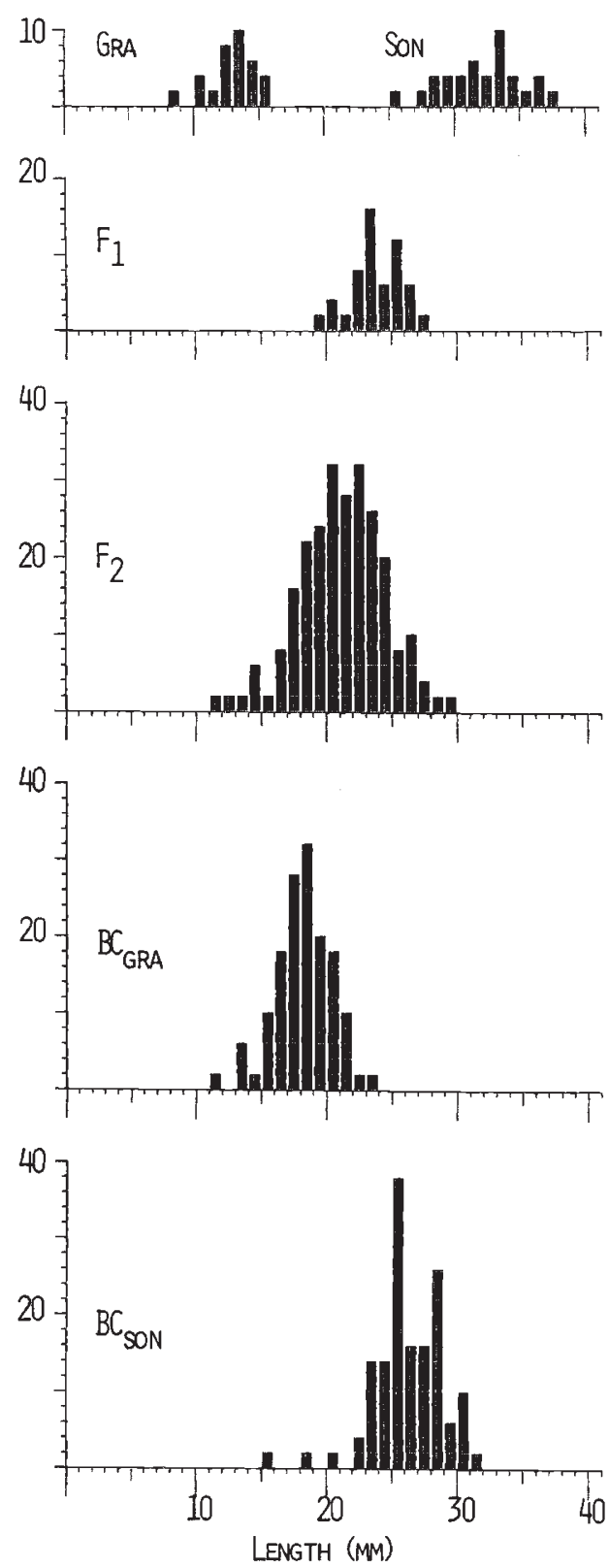

Figure 1 Histograms of petal length in subsp. gracilis (GRA), subsp. sonomensis ( $\mathrm{SON}$ ), their $\mathrm{F}_{1}, \mathrm{~F}_{2}$, and backcrosses to subsp. gracilis $\left(\mathrm{BC}_{\mathrm{GRA}}\right)$ and to subsp. sonomensis $\left(\mathrm{BC}_{\text {SON }}\right)$. The $\mathrm{F}_{1}$ and backcross data are each from two progenies combined. The $y$-axis gives number of plants of each type.

although plants grown under other conditions had no smudge. The $F_{1}$ had both central spot and basal smudge but lacked a basal spot.

The $F_{2}$ segregated $3: 1\left(\chi^{2}=0 \cdot 39\right)$ and the backcrosses to subsp. gracilis segregated $1: 1$ for central spot present versus absent (for progeny $\mathrm{A}, \chi^{2}=$ $0 \cdot 28$; for progeny $\mathrm{B}, \chi^{2}=0 \cdot 16$ ). These data indicate that the presence versus absence of central spot is governed by one locus.

Some $\mathrm{F}_{2}$ plants had distinct basal spots. Observation suggested that basal spot might be allelic to central spot, but the extreme variability of expression in this progeny made it difficult to distinguish plants with central spot only from plants with both central and (faint) basal spots. This situation was clarified by means of $\mathrm{F}_{3}$ progenies. Two $\mathrm{F}_{2}$ plants exhibiting both strong central and basal spots were self-pollinated and $\mathrm{F}_{3}$ progenies grown out (figs. $2(\mathrm{C})$ and $2(\mathrm{E})$ ). Both $\mathrm{F}_{3}$ progenies (numbers 223 and 226 in table 3) segregated sharply with $1 / 4$ having central spot only, $1 / 2$ both central spot and basal spot, and $1 / 4$ basal spot only (for progeny $223, \chi^{2}=0 \cdot 26$; for progeny $\left.226, \chi^{2}=0 \cdot 77\right)$. We conclude that spot position is determined by one locus, designated $P$. The subsp. sonomensis allele $P^{c}$ ( $c$ for central) confers a central spot. The other, codominant allele $P^{b}$ ( $b$ for basal) confers a basal spot and is necessarily derived from subsp. gracilis. Allelism between central and basal spots in the related $C$. rubicunda was previously reported by Rasmuson (1921).

\section{Basal petal spot expression}

Since subsp. gracilis has an allele for basal spot which is apparently not expressed, the phenotype may be modified by another locus or loci. As already mentioned, basal spot expression in the $F_{2}$ was highly variable, and the presence of intra-plant variability made scoring ambiguous in some cases. Among the $F_{2}$ plants which lacked a central spot (and, therefore, were $P^{b} P^{b}$ ) a distinct class had a strong, consistently expressed basal spot. This class comprised a quarter $\left(18 / 66, \chi^{2}=0 \cdot 18\right)$ of the plants lacking a central spot, suggesting that it was homozygous at a locus modifying basal spot expression. This possibility was tested by selfing three such $P^{b} P^{b} \mathrm{~F}_{2}$ individuals. The strong basal spot proved to be true-breeding $\left(\mathrm{F}_{3}\right.$ progenies 44 , 94 and 205 in table 3 ), consistent with the hypothesis.

The other individuals that lacked the central spot had variable basal spot expression (table 2). $\mathrm{F}_{3}$ progeny 114 was produced from a $P^{b} P^{b} \mathrm{~F}_{2}$ plant of the "weak basal spot" type, i.e., one that had some flowers with a well-defined but faint basal spot and other flowers with smudge only. This $F_{3}$ segregated into three classes: 9 individuals showed smudge only, 17 had basal spot with faint to intermediate expression like the $F_{2}$ parent, and 10 had 
Table 2 Segregation for presence versus absence of anthocyanin pigments and for position and type of petal spots in $F_{1}$, $F_{2}$, and backcross progenies between subsp. gracilis and subsp. sonomensis

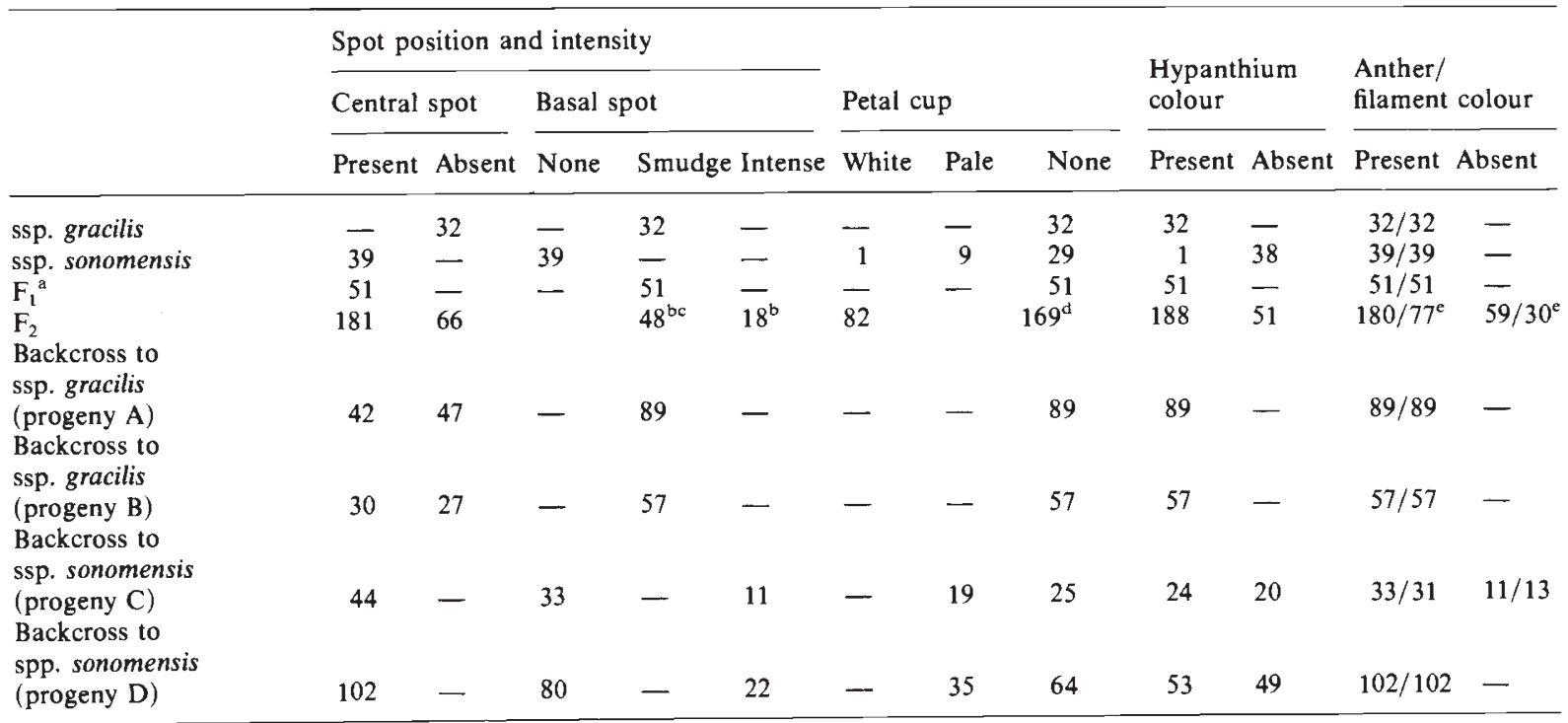

${ }^{a}$ Two progenies combined

${ }^{\mathrm{b}}$ Scored only for plants with central spot absent

${ }^{c}$ Combined data for none, weak, and smudge since distinctions not clear

${ }^{\mathrm{d}}$ Combined data for pale and none since distinction not clear

e Many plants were not scored for filament colour since it generally was the same as anther colour

Table $3 \quad F_{3}$ segregation for position and type of petal spots and for presence/absence of anthocyanin pigments

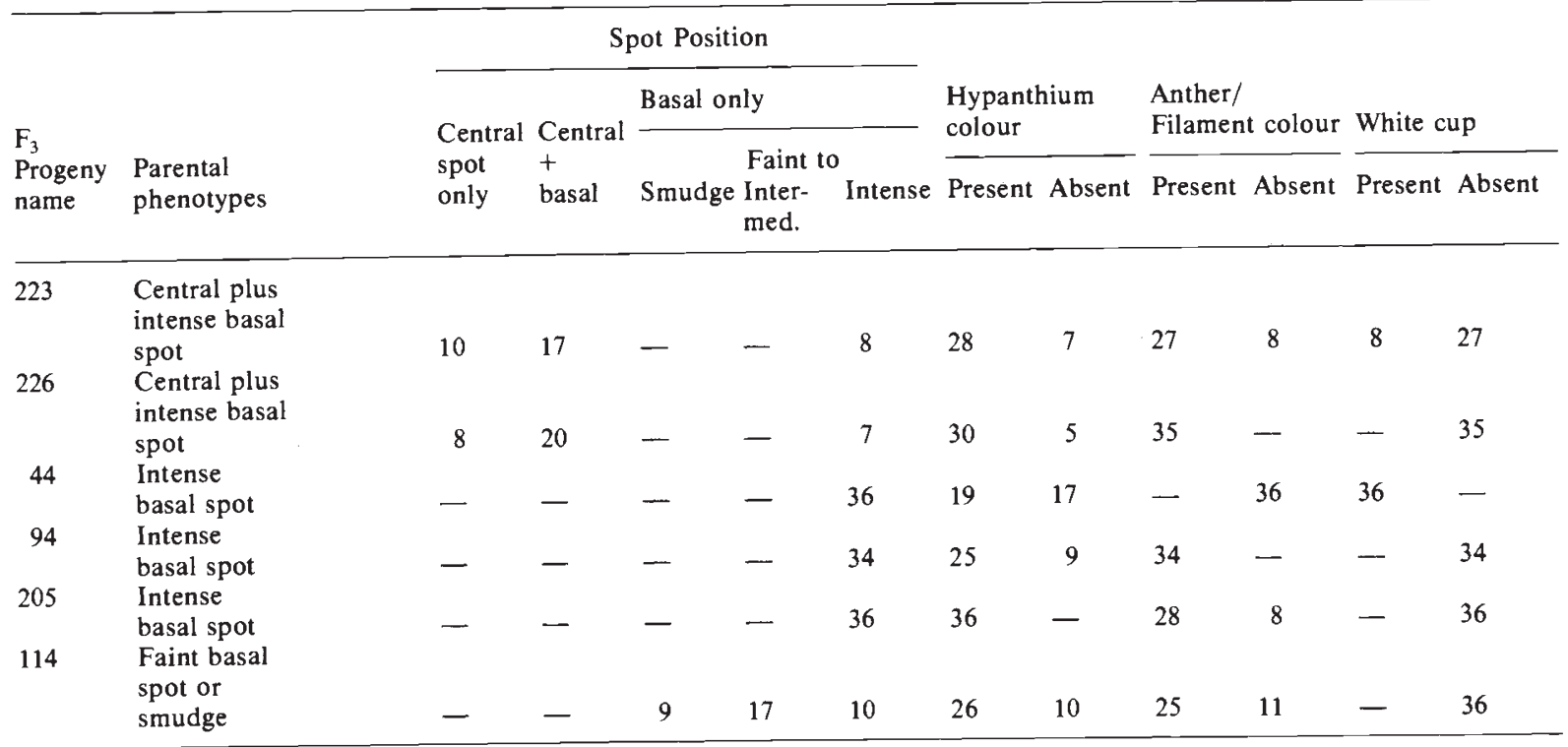

a strong basal spot (table 3 ). Although the numbers are small, the data conform closely to a $1: 2: 1$ ratio $\left(\chi^{2}=0 \cdot 17\right)$ and support the hypothesis that $P^{b} P^{b}$ individuals with a variable weak basal spot are heterozygous at a locus governing basal spot expression. Thus, at this locus, the alternative homozygotes have strong basal spot or smudge. Unfortunately $F_{3}$ progenies true-breeding for smudge were not grown.

The locus governing basal spot expression is designated $I / i$, with subsp. gracilis plants being $P^{b} P^{b} I I$ and subsp. sonomensis plants $P^{c} P^{c} i$. In 

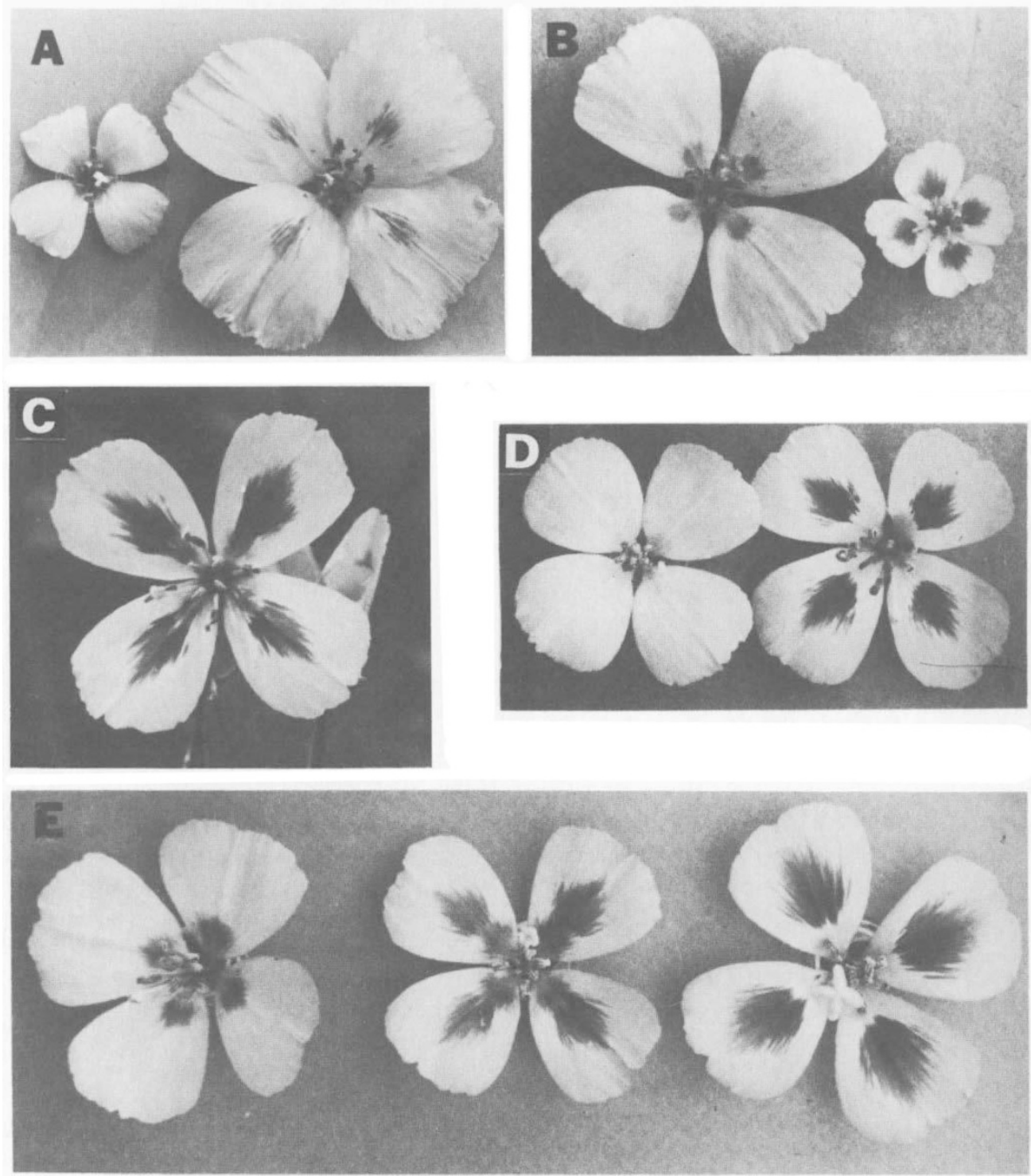

Figure 2 Photographs of flowers of parental and hybrid plants of C. gracilis: (A) subsp. gracilis (on left) and subsp. sonomensis. The petals of this individual of subsp. sonomensis had relatively small central spots. (B) Two $F_{2}$ recombinants, a large flower with basal spots and a small one with central spots. (C) A flower of $F_{2} 226$ with both central and basal spots. This plant was self-pollinated to give the $F_{3}$ progeny 226. (D) Two $F_{2}$ recombinants, both with medium-to-large flowers, one with typical central spots and the other without spots. (E) $F_{3}$ progeny 226 showing flowers with basal spots only, basal and central spots, and central spots only. The three patterns segregated $1: 2: 1$ (see table 3 ). 
the presence of position allele $P^{b}$, allele $i$ promotes or permits the expression of a distinct basal spot, while allele $I$ suppresses the spot and/or replaces it with a smudge. According to this model, the true-breeding $\mathrm{F}_{2}$ individuals with strong basal spot were $P^{b} P^{b}$ ii and the $\mathrm{F}_{2}$ individual with "weak basal spot" giving rise to $F_{3}$ progeny 114 had genotype $P^{b} P^{b} I i$. The effects of $I / i$ on basal spot expression appear to be similar whether on a $P^{b} P^{b}$ (basal spot only) or $P^{b} P^{c}$ (basal and central spots) background, but this has not yet been rigorously tested. The $I / i$ locus does not appear to affect the expression of central spot.

The backcross data (table 2) generally conform to this model. The two backcrosses to subsp. sonomensis segregated two classes of plants in a 3:1 ratio: central spot only (proposed genotypes $P^{c} P^{c} I i, P^{c} P^{c} i i$, and $\left.P^{b} P^{c} I i\right)$ versus both central and basal spots $\left(P^{b} P^{c} i i\right)$ (for progeny $C, \chi^{2}=0 \cdot 0$; for progeny $\left.D, \chi^{2}=0 \cdot 64\right)$. The backcrosses to subsp. gracilis segregated two classes of plants in a 1:1 ratio: smudge with central spot (proposed genotypes $P^{b} P^{c} I i$ and $\left.P^{b} P^{c} I I\right)$ versus smudge without central spot $\left(P^{b} P^{b} I i\right.$ and $\left.P^{b} P^{b} I I\right)$.

The nature of the variable expression of smudge remains to be resolved. For example, at the present time we propose that in the backcrosses to subsp. gracilis, $P^{b} P^{c}$ Ii exhibits both central spot and smudge (similar to the $F_{1}$ ), whereas in the backcross to subsp. sonomensis the phenotype is central spot only. We anticipate that our material, which was collected in the wild, will prove to contain modifiers at additional loci that affect this threshold trait. The issue will be settled in due course.

Since $I i$ individuals may have weak spot, smudge, or no spot depending on background, the dominance relationship of the alleles $I$ and $i$ is indefinite and the notation merely a convenience. We think of $P^{b}$ and $P^{c}$ as having a positive rather than merely permissive role in spot formation, but have no conclusive basis for this assumption. In spite of the unresolved details, it is clear that both subspecies contribute factors which in combination produce prominent basal spots in their $F_{2}$, although no basal spots are seen in either subspecies by itself.

\section{White cup}

The white cup locus was polymorphic within our sample of subsp. sonomensis (and invariant in subsp. gracilis). One plant had a bright white cup (designated $w w$ ) and nine plants had a pale cup and were probably heterozygous $(W w)$, with the remaining plants having uniformly pink petals $(W W)$. This fits Hardy-Weinberg expectation if $w$ has frequency $0 \cdot 14$ and heterozygote expression is intermediate in the subsp. sonomensis background. An individual with white cup was used as the subsp. sonomensis parent of the $\mathrm{F}_{2}$ progeny. No cup was evident in the $F_{1}$ (table 2), indicating that in the presence of subsp. gracilis genes, $W W$ and $W w$ are indistinguishable ( $W$ is dominant). In the $\mathrm{F}_{2}$, significantly more than one-fourth of the plants were scored as having white cup $\left(\chi^{2}=7 \cdot 87\right)$ (table 2 ), which we interpret to mean that on a segregating background some heterozygotes $W w$ are pale enough to look like homozygotes $w w$. The $\mathrm{F}_{3}$ progeny 223, with a more uniform background, showed an unambiguous $1: 3$ segregation $\left(\chi^{2}=\right.$ 0.09) (table 3).

All four backcross progenies should segregate $1: 1, W W: W w$. No pale cup was evident in either backcross progeny to subsp. gracilis. Backcross $\mathrm{C}$ to subsp. sonomensis segregated $1: 1\left(\chi^{2}=0 \cdot 82\right)$ for pale cup versus no cup, but backcross D was difficult to score and the results were skewed $\left(\chi^{2}=\right.$ 8.49) (table 2). The backcross data are consistent with the interpretation that $W W$ and $W w$ are indistinguishable in the presence of (some) genes from subsp. gracilis. Further tests to support this hypothesis and make it more precise have yet to be done.

No plants have both smudge and white cup. Since the genetic basis for smudge is not yet clear we cannot rule out the possibility that the absence of such plants results from some genetic linkage. However, another possibility is that the expression of smudge depends developmentally on the presence of background pigments in the basal region and thus smudge cannot be seen on $w w$ plants. This effect was one of the factors obscuring the scoring and interpretation of smudge in the $F_{2}$. Since $F_{3}$ progeny 44 (table 3 ) was truebreeding both for intense basal spot and white cup, evidently an intense expression of basal spot does not depend on the presence of background pigments.

\section{Back spot}

The petals of subsp. sonomensis displayed a spot on the back surface which partially overlapped the position of the central front spot but was generally slightly smaller and more basal. No segregation data are shown because in all progenies a back spot was present if and only if a central front spot was present. Variations in the size and intensity of this spot were complex and were not scored. 


\section{Hypanthium colour}

All individuals of subsp. gracilis had a dark red colouration of the hypanthium, while all except one plant of subsp. sonomensis lacked hypanthium colour. All plants of the $F_{1}$ were pigmented, and the $F_{2}$ segregated $3: 1(\chi=1 \cdot 71)$, presence versus absence (table 2), indicating that presence of anthocyanin pigmentation on the inner surface of the hypanthium is governed by a single locus, designated $H / h$, with presence of pigment dominant to absence. As expected, all plants in the backcrosses to subsp. gracilis were pigmented, and the backcrosses to subsp. sonomensis segregated $1: 1$ (for progeny $\mathrm{C}, \chi^{2}=0 \cdot 36$; for progeny $D, \chi^{2}=0 \cdot 16$ ) (table 2). Hypanthium colour segregated in five $\mathrm{F}_{3}$ progenies and four of these were consistent with the 3:1 model (table 3 ).

\section{Anther/filament colour}

The presence versus absence of pigments on the anthers and filaments was governed by a single locus, designated $C / c$, with presence dominant. All $F_{1}$ plants showed pigmentation, and the $F_{2}$ segregated $3: 1\left(180: 59, \chi^{2}=0 \cdot 01\right)$, presence versus absence (table 2). Both subspecies are characterized by pigmented anthers and filaments, but many individuals in subsp. sonomensis had lightly coloured anthers, suggesting that they were heterozygotes and that subsp. sonomensis was the source of the $c$ allele. The subsp. sonomensis parent of the $\mathrm{F}_{2}$ progeny may have been $C c$ or $c c$. That the $c$ allele is present in subsp. sonomensis was confirmed by the $3: 1$ segregation in backcross $C$ (table 2). Both the $F_{1}$ and subsp. sonomensis parents of this progeny must have been $C c$.

The anthers and filaments were almost always of the same colour; either both displayed anthocyanins or neither did. Fewer than 5 per cent of the plants had alternative expression on the two structures. Three models could account for these data. One model postulates one locus for stamen pigmentation, with the few variant individuals resulting from a non-genetic developmental failu re of anthocyanin expression. Another postulates an additional locus or loci modifying pigment distribution within the stamens. The third postulates two separate linked loci governing pigmentation of anthers and filaments respectively. These models have not yet been tested.

\section{Character correlation}

The correlation of central and back petal spots, of anther and filament pigmentation, and the fact that plants never show both white cup and smudge have been discussed above. The possibility of other phenotypic correlations in the $F_{2}$ between pairs of discrete traits was tested by chi-square analysis of $2 \times 2$ contingency tables. The results (not shown) revealed that spot position, white cup, hypanthium colour, and anther/filament colour assort independently. The difficulty in scoring basal spot expression precluded definitive assessment of the relationship of $I / i$ to the other discrete traits.

The possibility of a correlation between petal length or width and spot position, white cup, hypanthium colour and anther/filament colour was also tested. For each discrete trait, the $F_{2}$ was divided into two groups (e.g., central spot present versus absent). Petal length and width were compared in the two groups using the Mann-Whitney $U$ test. Because of the large $F_{2}$ sample size, the $U$ statistics were converted to standard deviates, using both the formula corrected for ties and the more conservative uncorrected formula (Sokal and Rohlf, 1981). Of the eight tests, only the test for length vs. hypanthium colour was significant at $P=0.05$.

\section{DISCUSSION}

Our genetic analysis of petal size and floral pigmentation patterns in Clarkia gracilis demonstrates single factor inheritance for petal spot position, basal spot expression, white cup, hypanthium pigmentation and anther/filament pigmentation. The inheritance of petal length and width is multifactorial. The $F_{2}$ included a very large array of floral types because nearly all the discrete traits segregated independently of each other and of the quantitative traits. The novel recombinants included many plants combining traits of both parents such as small flowers with central petal spots or large flowers with only a basal spot (figs. 2(B) and 2(D)). Many of these new combinations bred true in the $F_{3}$. The $F_{2}$ also exhibited substantial variation in the size and shape of the petal spots. Although we did not attempt an analysis of these variants, some of them were clearly heritable. Thus, one $F_{3}$ progeny showed a high incidence of a very narrow central spot, and another $\mathrm{F}_{3}$ consistently displayed central and basal spots that were large enough to overlap, creating the impression of one very large spot. Additional crosses are required to complete the analyses of several trait differences that appear to be modified by genetic background.

A number of the recombinant patterns identified in this study resembled floral features charac- 
teristic of other species of Clarkia, particularly those with bowl-shaped flowers like $C$. gracilis. For example, the flowers of many clarkias including C. arcuata, C. bottae, C. davyi and C. imbricata have white cup-like basal sectors. Flowers with unspotted petals are found in $C$. amoena subsp. lindleyi, $C$. arcuata, $C$. bottae, $C$. nitens and $C$. purpurea. Most species in section Godetia have petals with a large spot in a basal, central or distal position as well as additional patterning resulting from the juxtaposition of areas of white or cream and rose-purple. In addition to patterning on the petals, the species differ according to the presence/absence, intensity and type of pigmentation elsewhere in the flower. To a large extent, the organization of the pattern of floral pigmentation in different Clarkia species appears to include many of the same traits but in different combinations. Since Clarkia species do not make fertile hybrids, the genetic basis of their differences cannot be tested. But, it is plausible that the traits which show single factor inheritance in $C$. gracilis are governed in a similar manner in other clarkias. Although many loci presumably affect the details of floral pigmentation, it is likely that the inheritance of the major components of floral pattern in the genus is not complex.

The novel floral variants of Clarkia gracilis constructed during our analysis may be used to test hypotheses concerning floral form and pollination system. Appropriate variants can be introduced into different habitats and monitored to observe pollinator preferences and reproductive success. One approach would focus on the possible evolutionary significance of single discrete factors such as the spot position locus or hypanthium pigment locus. Such a study would address not only specific questions about particular loci (Do bees discriminate on the basis of hypanthium colour?), but also more general questions about whether allele substitutions with discrete morphogenetic effects have discrete ecological or evolutionary effects (Does any single locus have a significant effect on pollinator preference? Does selection proceed more rapidly when discrete floral traits are segregating in a population?). Alternatively, the resemblance of our recombinants to other Clarkia species could be exploited to study which aspects of floral pattern have been important in determining pollinator response in those other species.

In addition to its value for ecological studies, Clarkia gracilis may also prove useful as a model system to study the development of floral patterning. We began our study with several simple developmental hypotheses which we are already able to reject. The first hypothesis was that the petals of subsp. gracilis lack spots because the small size of the petal precludes spot development. This was rejected by the appearance in the $F_{2}$ of plants with small spotted petals.

Another hypothesis was that the induction of the central spot in the same position in each of the four petals of subsp. sonomensis involves physical contact with or proximity to another floral organ. The apparent contact in the young bud between the stamens and the central spot area of the unexpanded petals in subsp. sonomensis made this a plausible model. However, the occurrence of the basal spot in the $F_{2}$ suggests the model is unlikely since the basal spot region does not contact another organ. It remains possible that spots are induced by other organs with the inductive signals arriving via the vascular system.

A third hypothesis was that a spot consists of the derivatives of a single induced cell. This idea is apparently ruled out by the fact that some spots, especially "weak spots", consist of clusters of brightly pigmented cells, with the clusters separated by areas having only background levels of pigmentation. Thus a spot may be partly clonal, but its overall structure is complex. An anatomical examination of spots and smudges should precede any further speculation on this issue.

Although these early hypotheses were rejected, studies of the loci governing spot position, basal spot expression and white cup give rise to many questions concerning gene regulation and interaction. (When and how in development is spot position determined? What is the relationship between the establishment of background pigmentation and spots? What are the respective contributions of $P^{b}$ and $i$ to the occurrence and shape of the novel basal spot?) Also the correlated occurrence of central and back spots is of interest, since $P^{c}$ apparently confers two spots, one on each surface, while $P^{b}$ confers only one. Much of the current research into anthocyanin biosynthesis and regulation in horticultural plants can be exploited to study floral pattern regulation in Clarkia. The rich evolutionary background in Clarkia would give developmental studies particular value.

The recovery of a novel basal spot governed by a position allele from the unspotted subsp. gracilis poses questions about the origin of that allele. The other two subspecies tracyi and albicaulis have a band of basal colour which extends completely across the petal base, while the subsp. gracilis spot is small and more or less round, and does not extend to the edges of the petal 
(fig. 2). Since segregation at $I / i$ seems to affect primarily the density of pigmented cells, we provisionally think of the allele $P^{b}$ as conferring, at least in a gross sense, spot shape as well as position. We have not yet tested the allelism of the basal spot of subsp. gracilis with the basal bands of subspp. tracyi and albicaulis, but, regardless of the outcome of that test, the round basal spot appears to be novel in the species.

Most of the isozyme alleles of the tetraploid C. gracilis can be accounted for in the genomes of its diploid progenitors (Holsinger and Gottlieb, 1988). Spot types can be traced in the same way. $C$. amoena has a central spot and presumably its coding gene is ancestral to the gene for central spot in $C$. gracilis subsp. sonomensis. The basal bands expressed in $C$. gracilis subspp. tracyi and albicaulis probably derive from a species related to the diploid $C$. lassenensis, which also has a basal band. The other Clarkia species in the same section also have a basal band. Consequently, the subsp. gracilis spot and its encoding allele appear to be unique. The origin and persistence of the basal spot allele in subsp. gracilis is an evolutionary puzzle, since unexpressed traits are not subject (directly) to natural selection.

The sudden appearance of the basal spot in an $\mathrm{F}_{2}$ progeny also underscores the hazards of attempting to understand morphological evolution without genetic information. Were subsp. sonomensis and subsp. gracilis to hybridise in the wild, the novel spot would appear and might be selected and perpetuated. An observer would not know that the coding gene had already existed for some time. It is an interesting speculation that many loci include alleles that normally remain unexpressed. Segregation following hybridisation, frequent in plants, may place such alleles, as well as normally expressed alleles, under new patterns of regulation resulting in the abrupt appearance of novel forms.

\section{REFERENCES}

ABDEL-HAMEED. F. AND SNOW, R. 1968. Cytogenetic studies in Clarkia, section primigenia. IV. A cytological survey of Clarkia gracilis. Amer. J. Bot., 55, 1047-1054.

ABDEL-HAMEED, F. AND SNOW, R. 1972. The origin of the allotetraploid Clarkia gracilis. Evolution, 26, 74-83.

CORNU, A. AND MAIZONNIER, D. 1983. The genetics of Petunia. Janick, J. (ed.). In Plant Breeding Reviews, 1, 11-58.
DE WINTON, D. AND HALdANE, J. B. S. 1933. The genetics of Primula sinensis. II. Segregation and interaction of factors in the diploid. J. Genet., 27, 1-44.

DORN, P. S. AND BLOOM, W. L. 1984. Anthocyanin variation in an introgressive complex in Clarkia. Biochem. Syst. Ecol., 12, 311-314.

ENNOS, R. A. AND CLEGG, M. T. 1983. Flower color variation in the morning glory, Ipomoea purpurea. J. Hered., 74, $247-250$.

FINCHAM, J. R. S. AND HARRISON, B. J. 1967. Instability at the Pal locus in Antirrhinum majus. II. Multiple alleles produced by mutation of one original unstable allele. Heredity, 22, 211-224.

GOTTlieB, L. D. 1986. Genetic differentiation, speciation and phylogeny in Clarkia (Onagraceae). Iwatsuki, X., Raven, P. H. and Bock, W. J. (eds). In Modern Aspects of Species, University of Tokyo Press, Tokyo, pp. 145-160.

GotTlieB, L. D. AND WEEDEN, N. F. 1979. Gene duplication and phylogeny in Clarkia. Evolution, 33, 1024-1039.

Harland, S. C. 1929. The genetics of cotton. Part I. The inheritance of petal spot in new world cottons. J. Genet., 20, 365-385.

HOLSINGER, K. AND GOTTLIE B, L. D. 1988. Isozyme variability in the tetraploid Clarkia gracilis (Onagraceae) and its diploid relatives. Syst. Bot. (In press.)

HUTChInSON, J. B. 1932. The genetics of cotton. Part VIII. The inheritance of anthocyanin pigmentation in Asiatic cottons. J. Genet., 26, 317-339.

IMAI, Y. 1931. Analysis of flower color in Pharbitis nil. J. Genet., 24, 203-224.

LEWIS, H. 1973. The origin of diploid neospecies in Clarkia. Amer. Natur., 107, 161-170.

LEWIS, H. AND LEWIS, M. E. 1955. The genus Clarkia. Univ. Calif. Publ. Bot., 20, 241-392.

MACSWAIN, J. W., RAVEN, P. H. AND THORP, R. W. 1973. Comparative behavior of bees and Onagraceae. IV. Clarkia bees of the western United States. Univ. Calif. Publ. Entomology, $70,1-80$.

MOORE, D. M. AND LEWIS, H. 1965. The evolution of selfpollination in Clarkia xantiana. Evolution, 19, 104-114.

PHILP, J. 1933. The genetics of Papaver rhoeas and related forms. J. Genet., 28, 175-203.

RASMUSON, H. 1921. Beiträge zu einer genetischen Analyse zweier Godetia-Arten und ihrer Bastarde. Hereditas, 2, 143-289.

RILEY, H. P. $1945 a$. Inheritance of the main anthocyanin pigmentation and of some of its patterns in flowers of Nemesia strumosa. Bot. Gaz., 107, 32-51.

RILEY, H. P. $1945 b$. Inheritance of orange and yellow flower color in Nemesia strumosa. Bull. Torr. Bot. Club, 72, 435453.

RILEY, H. P. 1948. The eyebrow gene in Nemesia strumosa. $J$. Hered., 39, 170-172.

RILEY, H. P. 1949. Relationship of blue and orange flower color types in Nemesia strumosa. Bot. Gaz., 111, 43-52.

SOKAL, R. R. AND RHOLF, F. J. 1981. Biometry, 2nd ed., W. H. Freeman and Co., San Francisco, CA.

SOlTIS, P. S. 1986. Anthocyanidin variation in Clarkia (Onagraceae). Biochem. Syst. Ecol., 14, 487-489.

SYTSMA, K. AND GOTTLIEB, L. D. 1986a. Chloroplast DNA evidence and phylogenetic relationships in Clarkia sect. peripetasma (Onagraceae). Evolution, 40, 1248-1261.

SYTSMA, K. AND GOTTLIEB, L. D. 1986b. Chloroplast DNA evidence for the origin of the genus Heterogaura from a species of Clarkia (Onagraceae). Proc. Natl. Acad. Sci. USA, 83, 5554-5557. 